


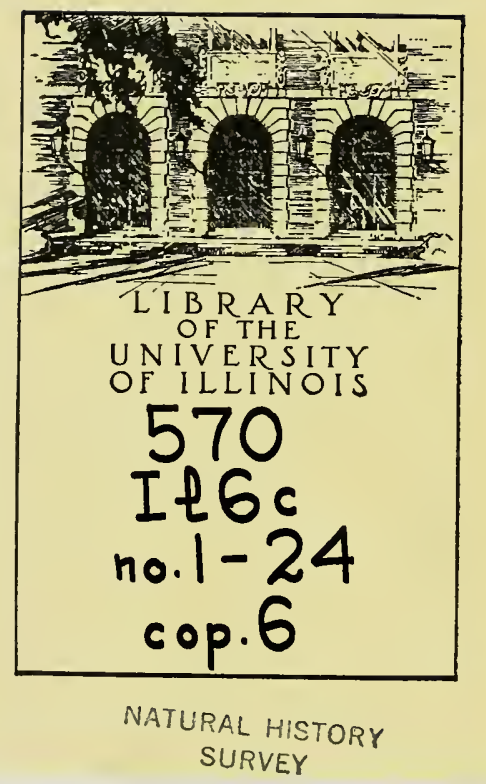


Digitized by the Internet Archive in 2011 with funding from

University of Illinois Urbana-Champaign 



State oe Illinois

Department of Registration and Education STATE NATURAL HISTORY SURVEY DIVISION

Stephen A. Forbes, Chief

Entomological Series

CIRCULAR 8

\title{
THE PEACH BORER AND METHODS OF CONTROL
}

\author{
By W. P. Flint and S. C. Chandler
}

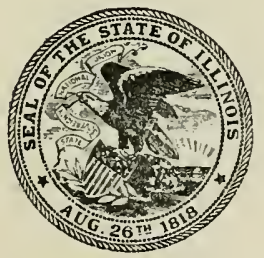

URBANA, ILLINOIS

4. of 1922 us. 


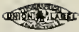

CLOVERLEAF PRESS JACKSONVILLE. ILLINOIS 


\title{
THE PEACH BORER AND METHODS OF CONTROL
}

\author{
By W. P. Flint and S. C. Chandler
}

The peach borer* is, in most localities, the worst insect enemy of the peach tree. Judging from recent experimental work, it can be easily and cheaply controlled by the use of para-dichlorobenzene (P. D. B.). $\dagger$

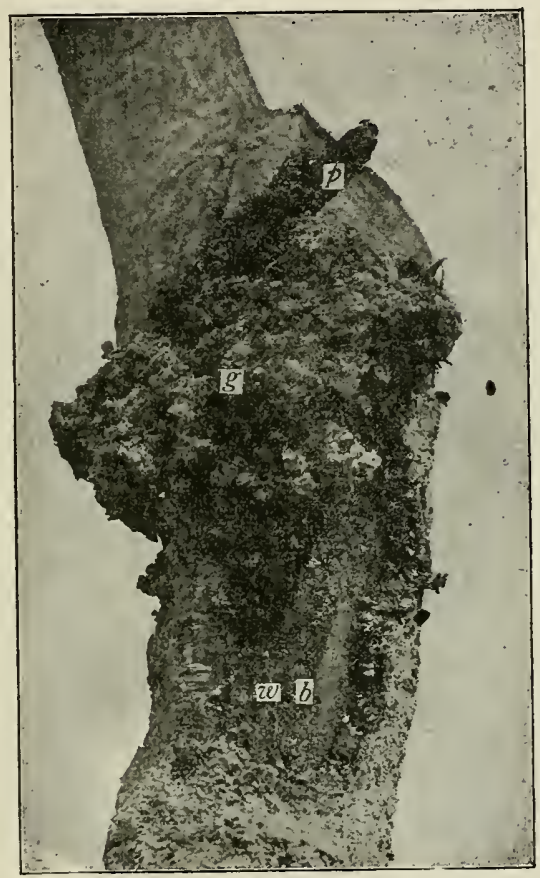

FIG. 1.

Trunk of peach tree injured by borer, showing mass of gum and protruding pupal case of the borer.

It would be very difficult to find a five year old peach tree anywhere in Illinois that has not been injured by the peach borer.

This insect always passes the winter in the inner bark of the peach tree as a pale white worm from one-quarter to one-half inch

*Aegeria exitiosa Say.

*As this name is difficult to remember and pronounce, it has been suggested that the abbreviation P. D. B. (Painless Death to Borers) be commonly used in preference to the longer term. 
in length. These worms will be found from ten inches above to six inches below the surface of the soil. They are most abundant just below the surface. Their presence in a tree is indicated by masses of gum mixed with brown frass or sawdust exuding from the injured trunk. (Fig. 1.) During the spring and summer the worms feed on the inner bark of the trees. They become full grown from the middle of June to the first of September. They then spin cocoons of silk, incorporating in them bits of frass. In these cocoons they change to a brown pupal stage, emerging from eighteen to thirty

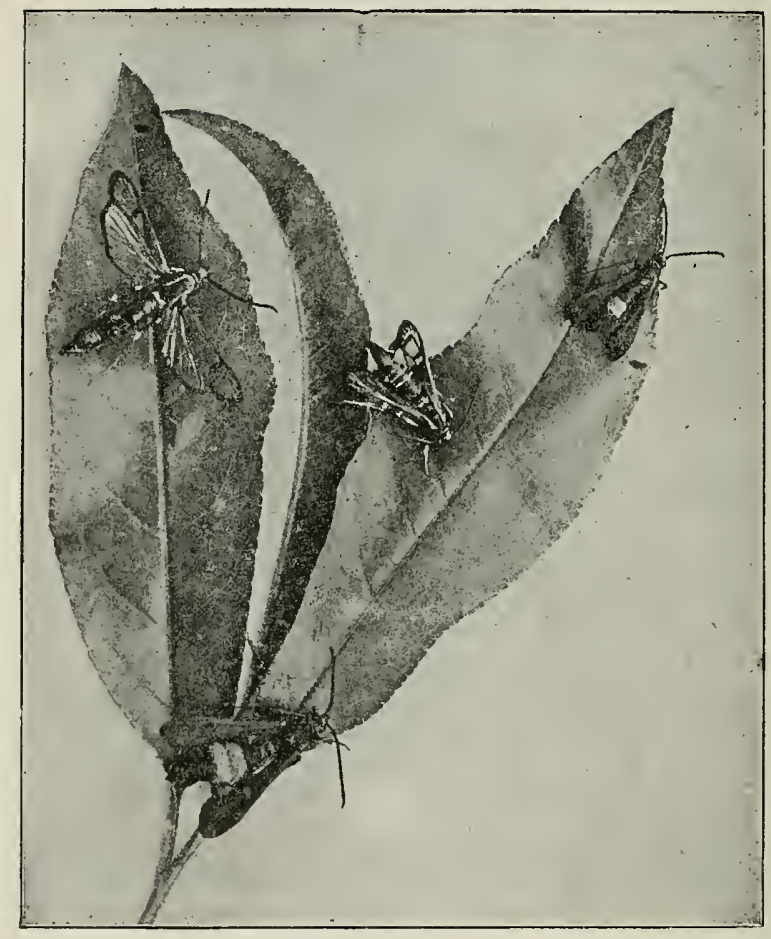

FIG. 2. Moths of peach borer on leaves.

days later as clear-winged moths. The moths have much the appearance of large wasps. (Fig. 2.)

The average life of the moths is six days, during which time the female lays from four hundred to one thousand eggs. The cggs are placed singly on or around the bases of the trunks of peach 
and related trees. In from seven to ten days small white worms with brown heads hatch from these eggs. They crawl over the outer bark and on finding a crack or wound rapidly eat their way in to the inner bark, where they continue to feed until cold weather. They remain dormant during the winter and resume feeding in the spring. (Fig. 3.)

There is but one brood a year, the moths emerging from July to October. Records made at Centralia, Illinois, show that young worms were hatching from July tenth to October tenth. At least $75 \%$ of the borers will hatch between the middle of August and the middle of September.

The injury to the trees is caused entirely by the worms, or larvae,

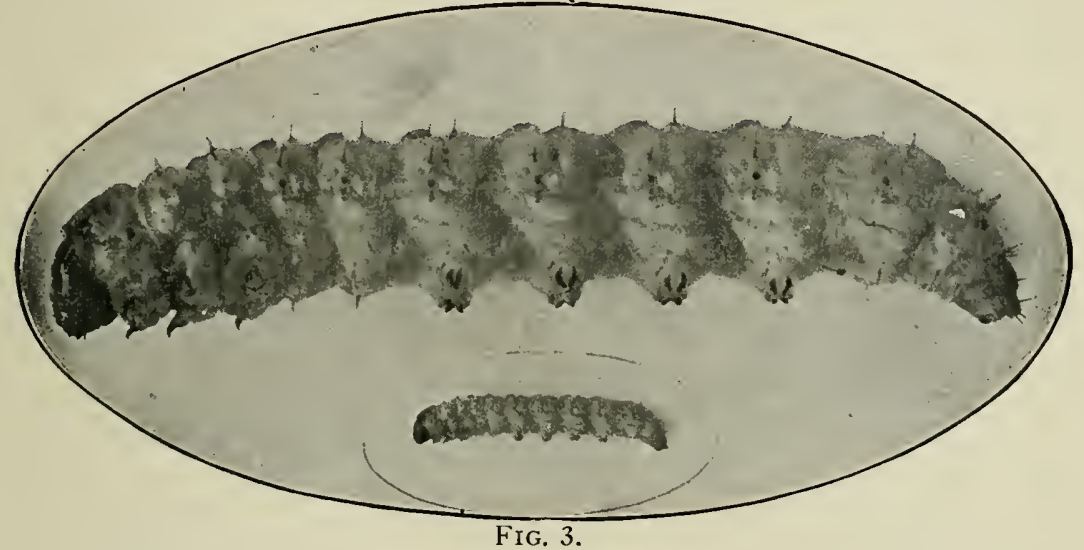

Larva of peach borer enlarged (above) and natural size (below).

feeding and boring in the inner bark of the lower trunk and large roots. The most serious injury is done to trees from two to four years old. Borers may be found in trees of all ages.

Until 1919 the only effective means known for controlling the borers was to cut or dig them out. This is best done after removing the earth from around the base of the tree, when the borers may be cut out with a sharp knife, following the grain of the bark. Burrows that can not be opened with a knife should be probed with a piece of flexible copper wire. It is generally necessary to go over an orchard twice each year, in October and in May. Care must be used in cutting or the injury done in this way may be as great as that caused by the borer. Even with thoro work it is seldom possible to get more than $90 \%$ of the borers. At best it is a very unsatisfactory method of control. 
A far more effective and cheaper means of destroying this insect has been discovered thru experiments of the Federal Bureau of Entomology. This work was later taken up in Illinois and in other states. The method consists in applying a small quantity of paradichlorobenzene (P. D. B.) crystals about the base of infested peach trees, and covering them with earth. These crystals volatilize and the gas from them, which is heavier than air, penetrates to the borers and kills them.

During 1920 and 1921 the Illinois Natural History Survey conducted a number of experiments in the use of this material. This work was carried on at Urbana, Farina, Carbondale, Anna, Cobden, and New Burnside. The para-dichlorobenzene was applied to trees of all ages from those in the nursery row to those five years old. Applications were made to blocks of trees at intervals during the spring and fall. A detailed account of these experiments is being published in the report of the Illinois Horticultural Society for 1921.

The information here presented regarding this method of treatment is drawn largely from the experimental work above mentioned. It can perhaps best be given by answering some of the questions frequently received regarding it.

\section{What is Para-dichlorobenzene (P. D. B.)?}

Para-dischlorobenzene is a white crystalline substance, the chemical formula for which is $\mathrm{C}_{6} \mathrm{H}_{4} \mathrm{Cl}_{2}$. To get the best results in borer-control the crystals should be fine enough to go thru a screen with ten meshes to the inch.

\section{How Does it Kill the Borers?}

When exposed, in the air or in soil, to a temperature of $60^{\circ} \mathrm{F}$. or above, the small crystals of the para-dichlorobenzene change to a gas which is heavier than air and penetrates the burrows of the borers. Exposure to moderate amounts of this gas is fatal to insects. Man and domestic animals are not injured except by prolonged exposure or by taking the crystals internally.

\section{How SHould it Be Applied?}

Para-dichlorobenzene should be applied to the cleaned surface of the ground around the base of the peach tree. All large masses of gum should be removed from the tree trunk. None of the crystals 
should be placed against the trunk of the tree, or more than two inches from it. Three or four spadefuls of earth should then be placed over the crystals. It is not advisable to dig the earth away from the tree before applying the para-dichlorobenzene. It will be well in cultivating to throw the earth away from the trees, instead of mounding it about them as has been generally done in the past. This will cause the adult borers to deposit their eggs lower on the trunk. The young borers can be more easily killed by the paradichlorobenzene method when they are near the surface of the ground. Figures 4, 5, 6, and 7 illustrate the steps to be taken in treating trees with P. D. B.

\section{How Much Para-dichlorobenzene should Be Used?}

It is necessary to have a sufficient amount of gas to kill the borers, regardless of the size of the tree. Experimental work in this state has shown that three-fourths of an ounce is sufficient for all trees from two to five years of age. Older trees with large trunks will require from one to one and one-half ounces. Very small trees may be treated with one-half of an ounce. A measure holding just the required amount is convenient for use in the orchard.

\section{When Should Para-dichlorobenzene be Applied?}

Judging from the experimental work in Illinois, the best results will be obtained when para-dichlorobenzene is applied in fall. Results from two years' treatments given from September 20th to October 25 th show from $95 \%$ to $100 \%$ of the borers killed. From $80 \%$ to $90 \%$ of the borers were killed by treatments given in late spring. From our present knowledge, the best time for treating in southern Illinois-or south of the Vandalia Railroad-is from September 25th to October 25th; north of this line, from September 20 th to October 20th. If the treatment is given in spring, the material should be applied between May 1st and 20th. If it is applied in summer or very early in fall, the tree may become reinfested by late-flying moths. If applied too early in spring or too late in fall the ground is not? warm enough to cause the para-dichlorobenzene crystals to vaporize and set free the gas in sufficient amounts to kill the borers. Soil temperature three inches below the surface should be at least $60^{\circ} \mathrm{F}$. One treatment per year, applied in fall, should be sufficient. 


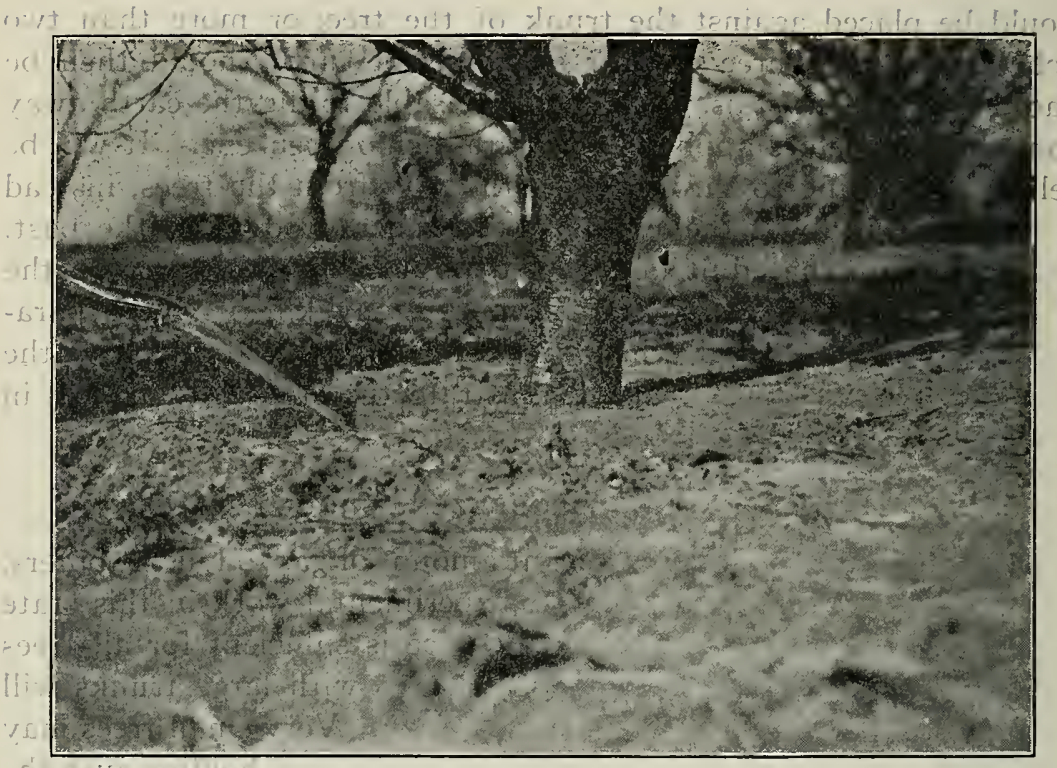

FIG 4. Leveling earth around the tree.

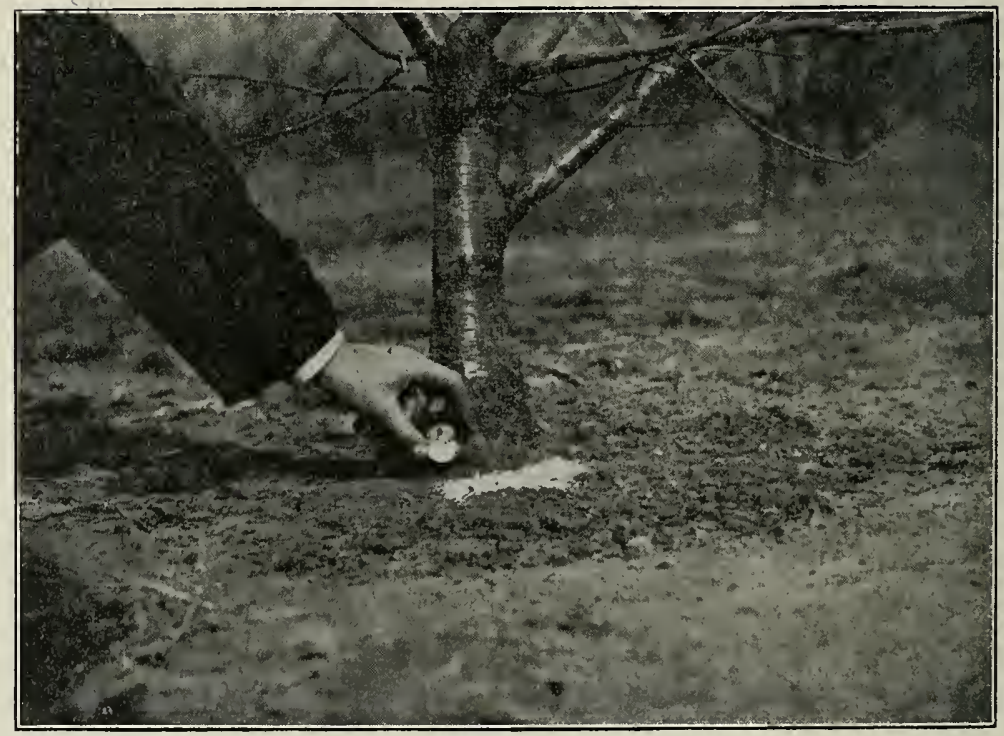

FIG. 5. Applying the P. D. B. 


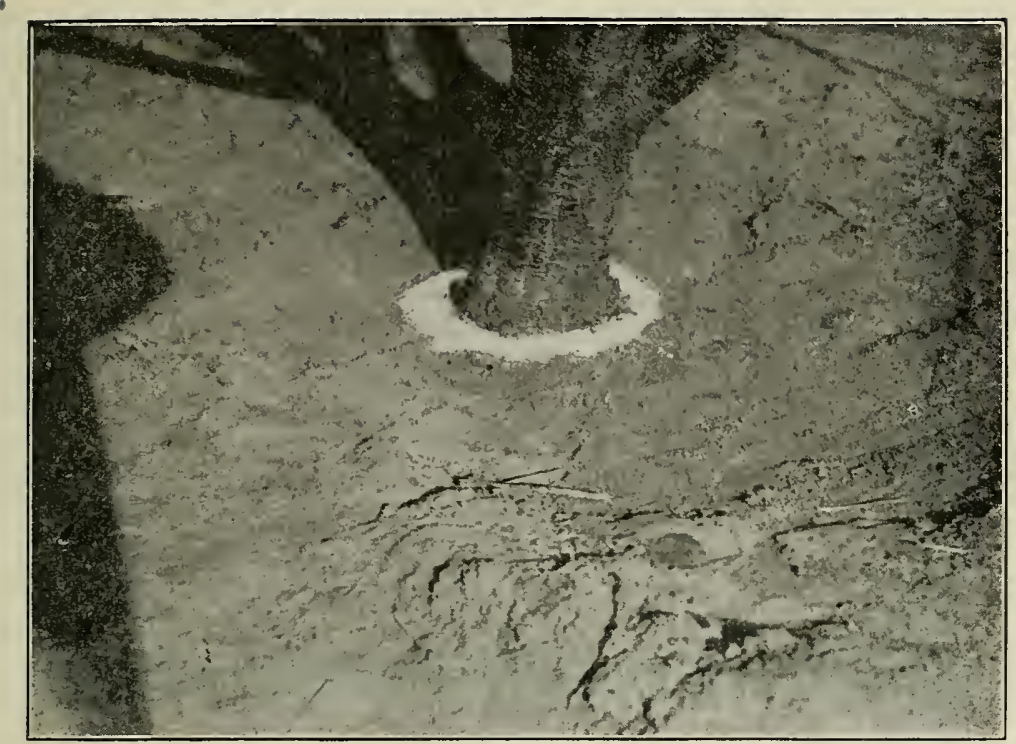

Fig. 6. P. D. B. in place around tree-trunk.

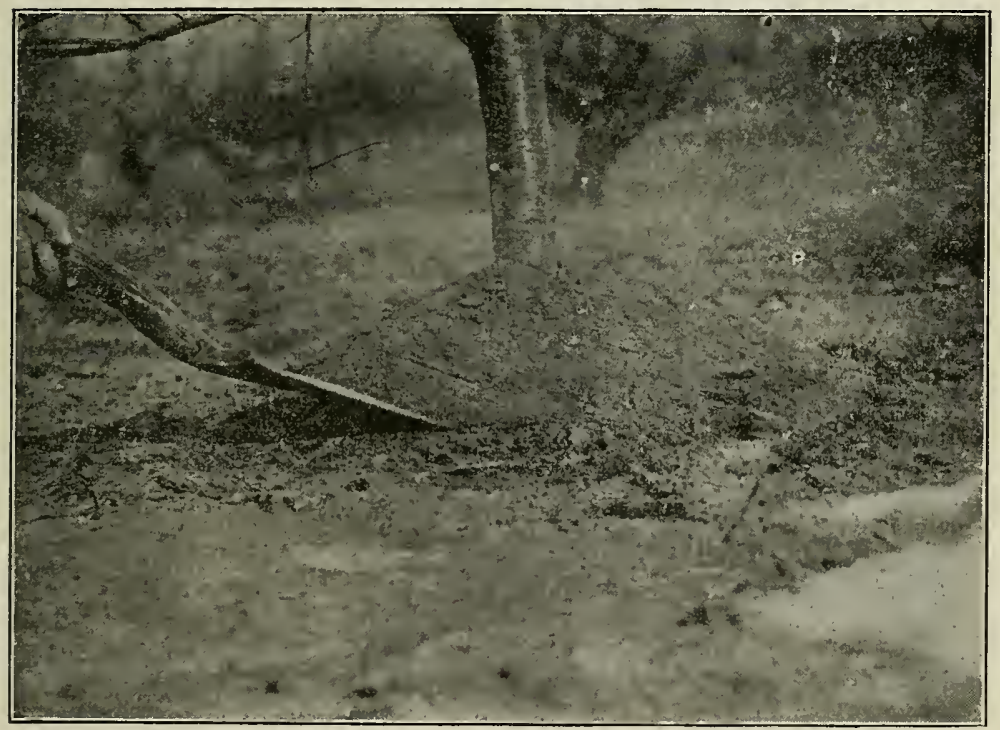

FIG. 7. Treated tree; P. D. B. covered with soil. 


\section{Is There ANy Danger of Killing Trees BY THIS TREATMENT?}

Thus far we have not killed any trees in this state where the above methods were used. Under different soil and weather conditions in other states trees have been killed. Judging from the results of our two years of experiments, this material is relatively safe. Further experiments are necessary before we can be sure of its effects on young trees. There is a chance that treatments given year after year may prove injurious, altho this is not likely.

\section{Should Pure Para-dichlorobenzene Be Used?}

Several companies have placed on the market, under trade names, a mixture of para-dichlorobenzene and other materials. The para-dichlorobenzene is the only chemical that has been found safe and effective for killing the peach borer. There is no reason for paying a high price for materials that are of no value in ridding the tree of the borers. Only the pure para-dichlorobenzene should be used.

\section{What does it Cost to Treat a Tree with PARA-DICHLOROBENZENE?}

At present, para-dichlorobenzene can be obtained for about $30 \mathrm{c}$. to $35 \mathrm{c}$. a pound in small quantities. In large amounts, it can be obtained for $17 \mathrm{c}$. to $20 \mathrm{c}$. a pound. Allowing $30 \mathrm{c}$. a pound, the cost for material would be $1 \frac{1}{2} \mathrm{c}$. a tree where three-fourths of an ounce was used. A man experienced in this work should be able to treat, on an average, fifteen to twenty trees an hour. Allowing twelve an hour, if the wage paid is $30 \mathrm{c}$. an hour, it would cost $2 \frac{1}{2} \mathrm{c}$. a tree for labor. This is a total cost of $4 \mathrm{c}$. a tree. In worming trees, if a careful and thoro treatment is given, it is difficult for a man to treat more than five an hour, which would cost $6 \mathrm{c}$. a tree; and it is generally advisable to worm in both fall and spring.

\section{On what Aged Trees should Para-dichlorobenzene BE ApPlied?}

Apparently it is safe to use para-dichlorobenzene under our conditions on any tree more than one year old. Experiments in Illinois have not resulted in any injury. Practically all of the trees treated in 1921 were only one year old. The only reason for not 
giving this material an unqualified recommendation is that experimental work in the East has shown some injury to young trees.

\section{What Effect has Wet Weather on the Results of Treatment with this Material?}

Illinois experiments on the hill-land orchards seem to show that the material is effective, even tho applied the day before or the day after soaking rains. In the spring of 1920 , for example, ten trees were treated in loess soil at Carbondale on May 15th. It rained every day for six consecutive days following, 3.97 inches falling from May 16th to 20 th. $77 \%$ of the worms found in these trees were killed. Records for southern Illinois showed eleven other cases where the material was effective in wet soil.

There is still need of several years' experimental work before we can make unqualified recommendations concerning the use of paradichlorobenzene. There are a number of points concerning the life history of the peach borer in this state on which work must be done. We also need more definite information concerning the effect of the gas on young trees, and on the cumulative effect of treatments. Further experiments will be carried on along these lines.

Following, is a partial list of the firms selling para-dichlorobenzene:

Hooker Electro-Chemical Co., 25 Pine St., New York City.

Merck \& Co., 45 Park Place, New York City.

Niagara Sprayer Co., Middleport, N. Y.

Interstate Chemical Co., Jersey City, N. J.

Rochester Germicide Co., Rochester, N. Y.

Meyer Bros. Drug Co., St. Louis, Mo.

E. C. Klipstein \& Sons Co., 644 Greenwich St., New York City.

International Chemical Co., Cleveland, Ohio.

General Chemical Co., 25 Broad St., New York City.

March 1, 1922. 






UNIVERSITY OF ILLINOIS-URBANA

5701L6C

CIRCULAR

1-24

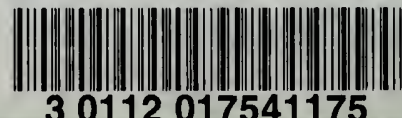

